\title{
Manganese Porphyrin Supported on Multiwalled Carbon Nanotube (MWCN) as Solid Catalyst for Alkene Epoxidation
}

\author{
G. Karimipour
}

\begin{abstract}
Two different Mn-porphyrins; Mn(TPP)OAc (TPP; tetraphenylporphyrin) and Mn(T4PyP)OAc (T4Py; tetra4-pyridylporphyrin) were prepared and their catalytic activities were determined in the epoxidation of alkenes with Oxone ${ }^{\circledR}\left(2 \mathrm{KHSO}_{5} \cdot \mathrm{KHSO}_{4} \cdot \mathrm{K}_{2} \mathrm{SO}_{4}\right)$. Mn(T4PyP)OAc was then immobilized on multiwalled carbon nanotube (MWCN) as solid support. The catalytic activity and efficiency of the prepated Mn(T4PyP)OAc@MWCN was studied and compared to the other catalysts. Mn(TPP)OAc and Mn(T4PyP)OAc are active than Mn(T4PyP)OAc@MWCN, however the later is more efficient than that that of the others, providing a turnover number of 342 and indicating the resistance of the Mn(T4PyP)OAc@MWCN to auto-degradation. The influence of $\mathrm{pH}$, the nature of the solvent and active intermediate was studied. The molar ratio of catalyst, co-catalyst (imidazole), substrate (alkene) and oxidant were found to be 1: 10: 50: 60 which seem to be the optimal molar amounts for alkene epoxidation. A catalytic cycle is postulated in which the intermediate involves interaction of $\mathrm{HSO}_{5}^{-}$with the Mn-porphyrin followed with oxidation of the alkene substrates.
\end{abstract}

Index Terms - Epoxidation, mn-porphyrin, multiwall carbon nanotube (MWCN).

\section{INTRODUCTION}

The feedstocks for many common compounds derived from petroleum products are oxygenated hydrocarbons such as aldehydes, ketones, alcohols and carboxylic acids. These in turn may be obtained by cracking petroleum which yields ethylene and other alkenes, and saturated hydrocarbons or from synthesis gas-derived methanol. Conversion of the produced hydrocarbons to oxygenated compounds utilizes transition metals as catalysts. In general, the best catalysts are both active (producing high yields rapidly) and selective (producing mainly the desired product). In this context, transition metal complexes of porphyrins as P450 enzyme mimics are well known for their ability to carry out a wide range of oxidation reactions in homogeneous systems [1].

However they readily undergo decomposition (due to self-oxidation) in solution phase. Therefore, immobilization of these catalysts to insoluble supports is particularly attractive as it should prevent this deactivation process. Further advantages of immobilization include simplified procedures for product purification and catalyst recovery and reuse [2].

Manuscript received August 3, 2013; revised December 4, 2013.

G. Karimipour is with the Department of Chemistry, Yasouj University, Yasouj 75918-74831, Iran (fax: +98-741-2223048; e-mail: ghkar@yu.ac.ir).

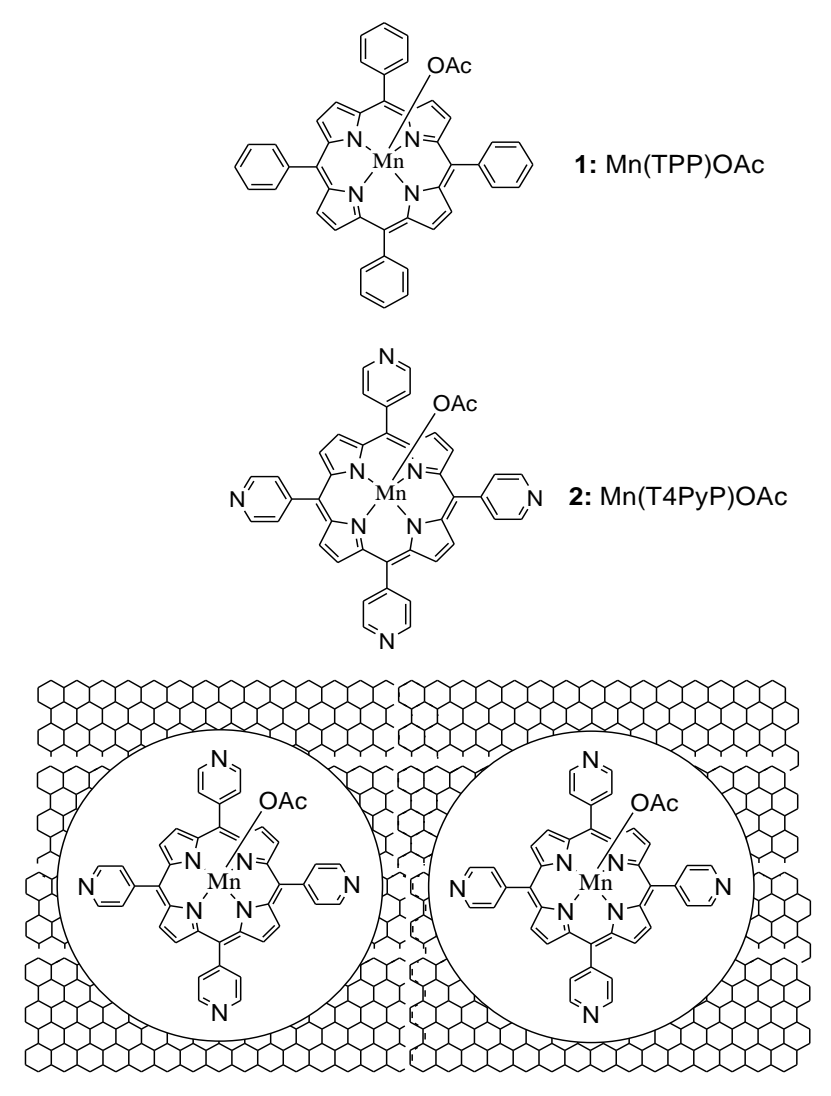

3: Mn(T4PyP)OAc@MWCNs

Fig. 1. Porphyrin used in this study.

In this study, we describe our investigations into the influence of catalyst in supported and unsupported forms on the oxidation of alkenes by Oxone ${ }^{\circledR}$ $\left(2 \mathrm{KHSO}_{5} \cdot \mathrm{KHSO}_{4} \cdot \mathrm{K}_{2} \mathrm{SO}_{4}\right)$ using $\mathrm{Mn}(\mathrm{TPP}) \mathrm{OAc}$, (1), Mn(T4PyP)OAc (2), and Mn(T4PyP)OAc@MWCN (3) (Fig. $1)$.

\section{EXPERIMENTAL}

All chemicals were of reagent grade quality obtained from commercial sources (Merck or Fluka) and used without further purification. The free base porphyrins: $\mathrm{TPPH}_{2}$ and $\mathrm{T}_{4} \mathrm{PyPH}_{2}$ were prepared and metalated by methods reported previously [3].

\section{A. Preparation of $M n(T 4 P y P) O A c @ M W C N ; 3$}

A mixture of $30 \mathrm{ml}$ concentrated nitric acid and $30 \mathrm{ml}$ concentrated chloridric acid were added to $10 \mathrm{~g}$ MWCN and the resulted suspension refluxed for 24 hours. Then it was filtered, washed with distillated water till $\mathrm{pH}$ arrived around 7 
and dried in $110^{\circ} \mathrm{C} .1 .5 \mathrm{~g}$ of prepared functionalized MWCN was then added to $50 \mathrm{ml}$ of $\mathrm{CH}_{2} \mathrm{Cl}_{2}$ and $0.15 \mathrm{~g}$ of $\mathrm{Mn}$ (T4PyP)OAc was added into the mixture and refluxed for 24 hours. Under this condition, Mn(T4PyP)OAc interacted with MWCN. After cooling the reaction flaks, $\mathrm{Mn}(\mathrm{T} 4 \mathrm{PyP}) \mathrm{OAc} @ \mathrm{MWCN} ; 3$ was filtered and dried in $110^{\circ} \mathrm{C}$ for 4 hours.

\section{B. Procedure for Catalytic Oxidation}

In a $5 \mathrm{ml}$ vessel containing $0.4 \mathrm{ml} \mathrm{EtOH}$ and $0.8 \mathrm{ml} \mathrm{H}_{2} \mathrm{O}$, $0.05 \mathrm{mmol}$ of alkene, $0.01 \mathrm{mmol}$ of imidazole (as co-catalyst) were added to $0.001 \mathrm{mmol}$ of the catalyst. After djusting of $\mathrm{pH}=4.5$ with acetic acid, $0.06 \mathrm{mmol}$ of Oxone ${ }^{\circledR}$ $\left(2 \mathrm{KHSO}_{5} \cdot \mathrm{KHSO}_{4} \cdot \mathrm{K}_{2} \mathrm{SO}_{4}\right)$ was added to the vessel. The reaction was stirred for required time at $25^{\circ} \mathrm{C}$ and the yields based on the alkene substrates were determined by GC (Agilent 6890N; USA with SE-30 packed column) using chlorobenzene as the internal standard.

\section{RESULTS AND DISCUSSION}

1 and 2 were prepared by the reaction of $\mathrm{Mn}(\mathrm{OAc})_{2} \cdot 4 \mathrm{H}_{2} \mathrm{O}$ with $\mathrm{H}_{2}$ TPP and $\mathrm{H}_{2}$ T4PyP as free base porphyrin ligands [4]. The UV-Vis analysis of 1 and 2 shows intense Soret bands at 478 and $461 \mathrm{~nm}$ respectively with some Q-bands at 500-700 $\mathrm{nm}$ region for both complexes, characteristic of the manganese (III) porphyrins (Fig. 2) [4].

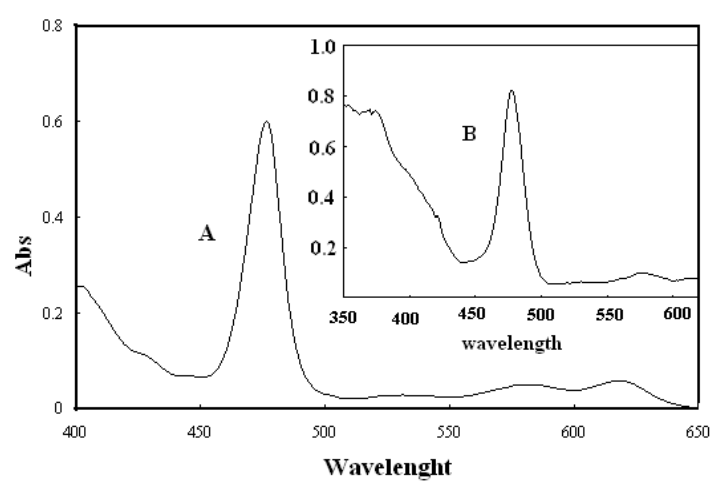

Fig. 2. UV-Vis spectrum of $1(\mathrm{~A})$ and $2(\mathrm{~B})$ in $\mathrm{CH}_{2} \mathrm{Cl}_{2}$.

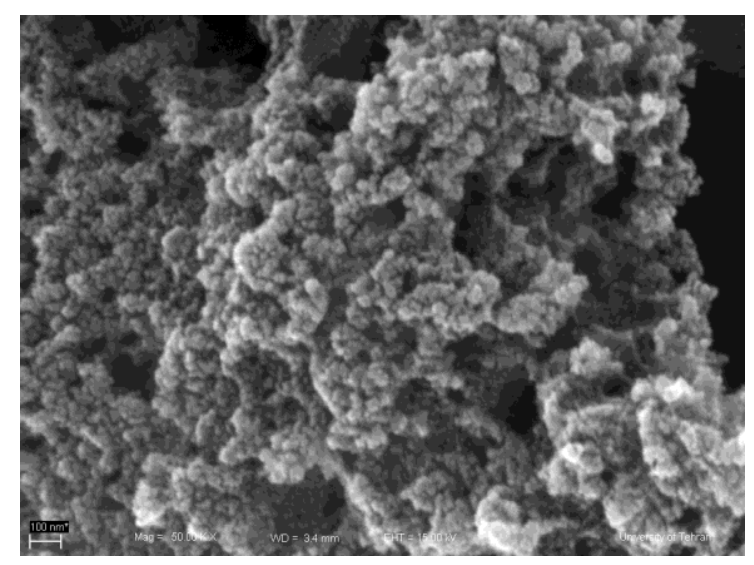

Fig. 3. SEM image of 3.

Multi-walled carbon nanotube (MWCNT) was activated by a simple acid refluxing process and interacted with $\mathrm{Mn}$ (T4PyP)OAc (2) to prepare Mn(T4PyP)OAc@MWCN; 3 as solid catalyst, in which the chemical interactions between the $\mathrm{Mn}$ atoms and/or pyridyl groups and MWCN was suggested to be covalent and non-covalent.

Fig. 3 shows the SEM image of 3 with magnification of 10000. The instrumental parameters, accelerating voltage, spot size, and magnification and working distances are indicated on SEM image. We can observe that 2 is deposited effectively on MWCN, providing a uniform surface contain a homogeneous arrangement of 2 at MWCN. Moreover, the catalyst was dispersed on the surface of the MWCNT with an average particle size of $\sim 50.0 \mathrm{~nm}$.

\section{OXIDATION}

The oxidation reactions were carried out following the method described in our previous works [5] using 1, 2 or 3, imidazol, alkene and Oxone $\AA$ as catalyst, co-catalyst, substrate and oxidant, respectively. Using $0.001 \mathrm{mmol}$ of the required catalyst, the molar ratio of the catalyst, co-catalyst, substrate and oxidant were found to be 1: 10: 50: 60 .

This is the optimal molar ratios, because the epoxidation of alkenes was achieved at short time with high yield under this condition.

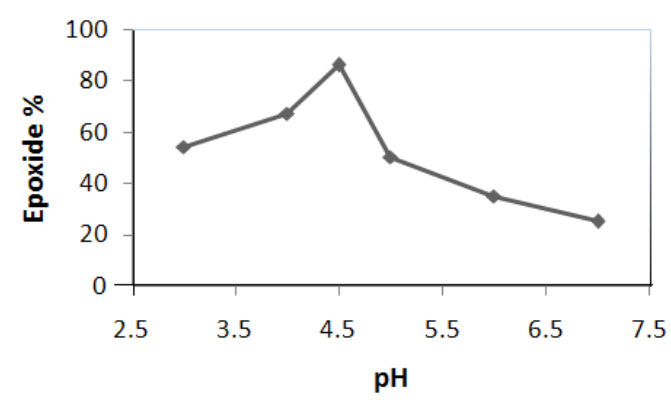

Fig. 4. Influence of $\mathrm{pH}$ on the epoxidation of $\alpha$-methylstyrene.

We found that that $\mathrm{EtOH} / \mathrm{H}_{2} \mathrm{O}$ is the best solvent among the $\mathrm{CH}_{2} \mathrm{Cl}_{2}, \mathrm{CH}_{3} \mathrm{CN}, \mathrm{CH}_{3} \mathrm{CN} / \mathrm{H}_{2} \mathrm{O}$ and $\mathrm{EtOH} / \mathrm{H}_{2} \mathrm{O}$, since $\alpha$-methylstyrene is oxidized selectively to the corresponding epoxide with high yield.

TABLE I: EPOXIDATION OF ALKENES WITH 2/IM- OXONE® CATALYTIC SYSTEM IN ETOH/ $\mathrm{H}_{2} \mathrm{O}$

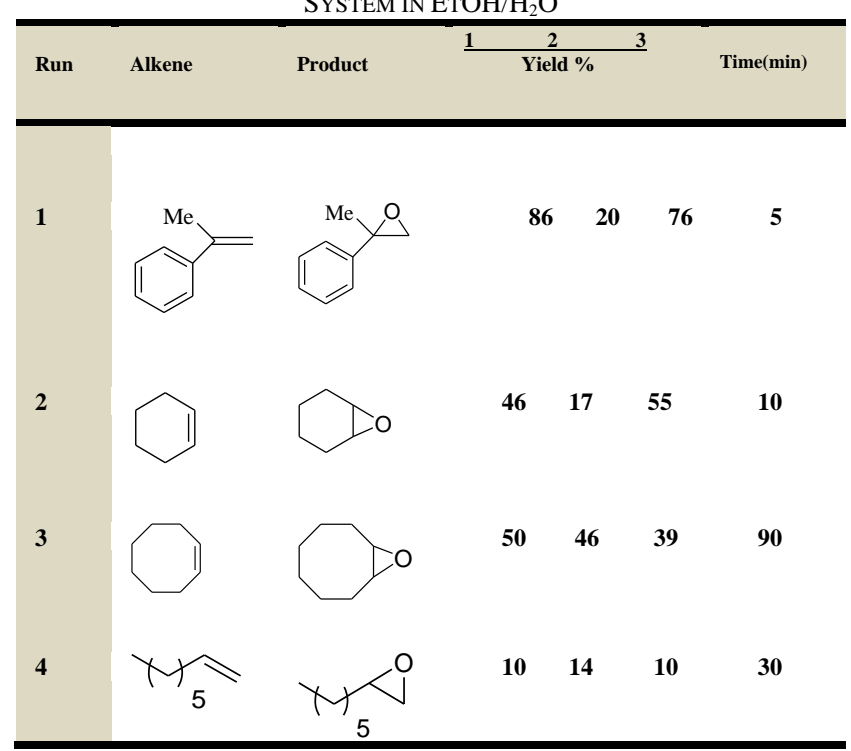

It can be seen that the epoxide formation is very depended 
on $\mathrm{pH}$ and the maximum $\alpha$-methylstyrene epoxide was obtain at $\mathrm{pH}=4.5$ (Fig. 4). So the optimal molar condition of reagents, solvent and $\mathrm{pH}$ described here was applied for a number of alkenes and the excellent results are summarized in Table I.

It is clear that both steric and electronic factors of alkenes affected on the yield and time of the epoxidation reactions. For instance, electron-rich $\alpha$-methylstyrene (run 1) is more reactive than cyclohexene (run 2) for epoxidation by the Mn-Por/Oxone-Im catalytic system. Moreover, 1-octene (run 4) as a linear alkene with inherent steric properties displays lower activity in this alkene series (Table I).

Reviews of the literature on metalloporphyrins show that the reaction yield represents the catalytic activity and turnover number (TON: the ratio of the number of moles of produced epoxide to the number of moles of catalyst) is a characteristic of the catalytic efficiency of the catalysts. In the epoxidation of $\alpha$-methylstyrene with Mn-Por/Oxone-Im, it is clear that 1 is the active among the catalysts (Fig. 5). The catalyst 2 displayed the lowest activity, leading to only $20 \%$ epoxide yield. However, a comparison between TONs obtained with 1, 2 and 3 under similar conditions; show that the later is more efficient than shows that the latter is more efficient and hence is appropriate as an effective, stable and reusable catalyst.

As shown in Fig. 5, 3 exhibited efficiency higher than that of 1 and 2, since 3 displayed highest turnover number (342 cycle) [4]. These observations clearly show that catalyst 2 lose its catalytic activity under the epoxidation reactions because of destruction of the porphyrin framework during the catalytic cycle. However, immobilization of 2 on MWCN allows obtaining an easy recycling solid catalyst 3 , which can be used several times without significant losing of its activity.

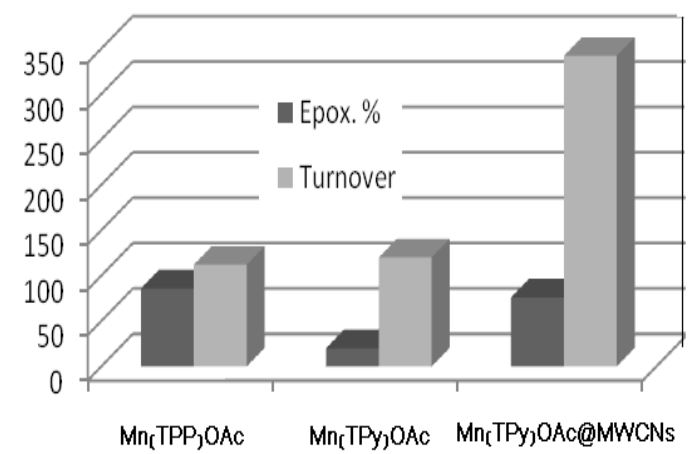

Fig. 5. Catalytic activities of 1,2 and 3 .

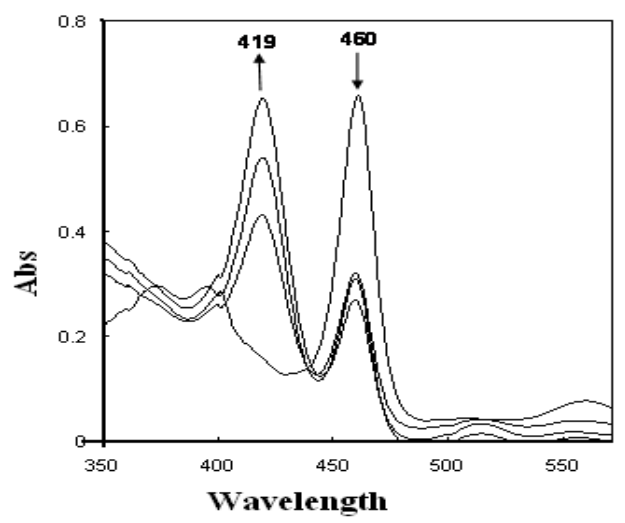

Fig. 6. UV-Vis spectrum of $1(\mathrm{~A})$ and 2 (B) in $\mathrm{CH}_{2} \mathrm{Cl}_{2}$.
It has been believed for a long time that oxoiron(IV) porphyrin $\pi$-cation radicals [6] are the sole reactive species involved in cytochrome $\mathrm{P} 450$-catalyzed oxidation reactions and the reactive intermediate represent unique spectroscopic future. As shown in Fig. 6, electronic absorption spectra of 2 with Soret band appear at $460 \mathrm{~nm}$ was converted into a spectrum with a high absorption at $419 \mathrm{~nm}$ during the epoxidation of $\alpha$-methylstyrene with Oxone ${ }^{\circledR}$-Im system in EtOH/ $\mathrm{H}_{2} \mathrm{O}$. This spectroscopic alterations are nicely confirmed the formation of Oxo-Mn(IV) porphyrin in alkene epoxidation with the Mn-porphyrins [4].

As shown in Fig. 7, the catalytic cycle may involve the interaction of imidazole and $\mathrm{HSO}_{5}{ }^{-}$(Oxone) with the $\mathrm{Mn}$-catalysts to form oxo-Mn(IV) porphyrin species as active intermediates. The final step of the cycle engaged the reaction of alkene with the oxo-species. In conclusion, metalloporphyrins are important biological molecules that fulfill a variety of functions in nature. For example, iron-containing hemoglobins are metalloporphyrins that bind cooperatively to oxygen and act as oxygen transporters in vertebrates.

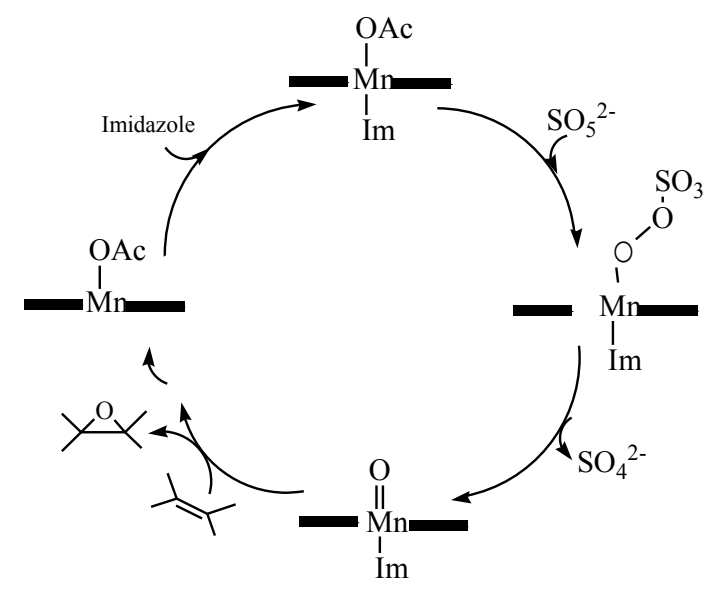

Fig. 7. A simple catalytic cycle for alkene epoxidation by Mn-porphyrins and Oxone.

One important problem is the degradation of metalloporphyrin catalyst in organic oxidations. In this work Mn(T4PyP)OAc@MWCN; 3 as a solid catalyst was prepared and found to be an efficient catalyst than homogenous $\mathrm{Mn}(\mathrm{TPP}) \mathrm{OAc}$ and Mn(T4PyP)OAc complexes. The highest turnover of $\mathrm{Mn}(\mathrm{T} 4 \mathrm{PyP}) \mathrm{OAc} @ \mathrm{MWCN}$; 3 (in comparison with $\mathrm{Mn}(\mathrm{TPP}) \mathrm{OAc}$ and $\mathrm{Mn}(\mathrm{T} 4 \mathrm{PyP}) \mathrm{OAc}$ ) and its resistance to degradation are the highlights of this catalyst. We have found that epoxidation of alkenes was affected by $\mathrm{pH}$ of the reaction. Moreover, the electronic and steric properties of the alkenes as well as the Mn catalysts affected the yield and turnover number and the time of the reaction. The intermediate involve an Oxo-porphyrin responsible of alkene epoxidation was proposed with smile catalytic cycle.

\section{ACKNOWLEDGMENT}

The financial support of this work by Yasouj University Research Councils is acknowledged.

\section{REFERENCES}

[1] J. H. Dawson and M. Sono, "Cytochrome P-450 and Chloroperoxidase: Thiolate-Ligated Heme Enzymes, Spectroscopic Determination of 
Their Active Site Structures and Mechanistic Implications of Thiolate Ligation" Chem. Rev. vol. 87, pp. 1255, 1987.

[2] S. Nakagaki, F. L. Benedito, and F. Wypych, "Anionic iron (III) porphyrin immobilized on silanized kaolinite as catalyst for oxidation reactions" J. Mol. Catal: A, vol. 217, pp. 121, 2004.

[3] A. D. Adler, F. R. Longo, J. D. Finarelli, J. Goldmacher, J. Assour, and L. Korsakoff, “A simplified synthesis for meso-tetraphenylporphine," $J$ Org. Chem, vol. 32, pp. 476, 1967.

[4] D. Mohajer, G. Karimipour, and M. Bagherzadeh, "Reactivity studies of Biomimetic Catalytic Epoxidation of Alkenes with Tetrabutylammonium Periodate in the Presence of Various Manganese Porphyrins and Nitrogen Donors: Significant Axial Ligand п-Bonding Effects," New. J. Chem, vol. 28, pp. 740, 2004.

[5] G. Karimipour, B. Karami, M. zohori, and S. Zakavi, "Oxidative Decarboxylation of Carboxylic Acids with Tetrabutylammonium Periodate Catalyzed by Manganese (III) Meso-Tetraarylporphyrins: Effect of Metals, Meso-Substituents, and Anionic Axial Ligands," Chin J. Catal, vol. 28, pp. 940, 2007
[6] W. Nam, Y. O. Ryu, and W. J. Song, "Oxidizing intermediates in cytochrome P450 model reactions," J. Biol. Inorg. Chem, vol. 9, pp. $654,2004$.

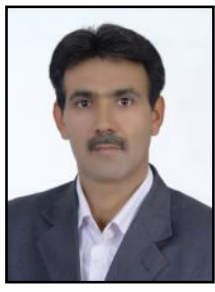

Gholamreza Karimipour was born in Shiraz, Iran, in 1967. He received the B.Sc., M.Sc., and Ph.D. degrees from Shiraz University, Shiraz. He is currently an associate professor of inorganic chemistry with Yasouj University, Yasouj, Iran. He has presented more than 40 papers at scientific conferences and has published more than 17 scientific papers and has supervised 27 graduate and $3 \mathrm{PhD}$ students. Recently, he has focused his efforts on the immobilized metalloporphyrins as heterogeneous catalysts for industrial purposes. His current research interests include biomimetic oxidation catalyzed by metalloporphyrins. Dr. Karimipour is a senior member of the Asia-Pacific Chemical, Biological and Environmental Engineering Society. 